\title{
Increasing burden of COPD in rural India: an example why India warrants primary healthcare reforms
}

\section{To the Editor:}

India is experiencing a continued increase in burden of chronic obstructive pulmonary disease (COPD). With an estimated prevalence of $>57000000$ people suffering from obstructive airway diseases (OADs), by the end of 2016 [1], India is in second place for harbouring the most number of morbidity and mortality cases from OADs, after China. As per the countrywide estimates of the World Health Organization, the COPD morbidity assessed with disability adjusted life years was 690 per 100000 population in 2004 [2]. This is likely to be enormously high in a country with a population of 1.25 billion. The age standardised death rate of 64.7 per 100000 population accounts for $20 \%$ of the annual worldwide COPD mortality (556000 out of 2748000 cases) [3]. In a recent single-day point prevalence study across India (POSEIDON) study, $14.5 \%$ of people had visited a physician for OADs [4]. However, most of the information was obtained from private facilities within urban areas and, therefore, unlikely to reflect the true burden of disease; particularly in rural India where prevalence of COPD is reported to be even higher and is continuously increasing [1]. Similarly, the estimated economic burden of COPD (2010-2011) was more than six billion dollars and expected to rise to eight billion dollars by the end of 2016 [1].

Exposure to biomass combustion fuels inside the home, which lead to hazardous indoor air effluents that are associated with an increased of COPD, is worse in the rural areas where houses are more poorly ventilated [5]. Added to this, the non-conventional forms of tobacco products such as bidi, hookah, chillum, which deliver relatively greater amounts of combustion by products, are excessively consumed in the rural areas. Poorly regulated occupational exposures to vapours, dusts, gases and fumes also contribute to an increased prevalence.

There are significant gaps in primary healthcare delivery and clinical approach to the management of COPD and other airway diseases. Lack of awareness tends to under estimate disease prevalence and progression. The disease remains inadequately managed since most of the primary healthcare units are not equipped with minimal instrumental facilities. Primary care physicians are either not aware of or not sensitised to the use of inhalers in disease management. A substantial amount of rural and suburban people rely on practitioners of alternative medicine, such as homeopathy, Unani and Ayurveda, most of whom do not recognise the disease as a distinct clinical entity. Even smoking cessation is rarely advised in the routine medical prescriptions [6]. Of five important operation problems for the delivery of universal healthcare coverage, scarcity of human resources in the primary care units particularly in disadvantaged areas, lack of governance and poor reliability were crucial [7].

Unfortunately, most of the proposed approaches to upgrade primary healthcare have not yet taken shape. There is a need to adopt a multipronged framework approach involving the reduction of risk factors, improving availability of health personnel and other infrastructure such as drugs and devices, implementation of standard treatment guidelines, a functional referral mechanism, the introduction of pulmonary rehabilitation programmes, and effective surveillance systems [8]. Tobacco control, reduction of household and ambient air pollution and occupational exposures are important steps to reduce the risk [9]. Academic and professional upgradation of the healthcare personnel should be done on a high-priority basis. Patient counselling and patient education should be given top priority. There is unquestioned need to raise the standard of the primary healthcare units through upgradation of diagnosis and treatment facilities. Easy availability of spirometry and affordable common drugs including inhalers (long and short-acting bronchodilators and corticosteroids) is important for disease control and management. It is also important to adhere to standard treatment guidelines linked to issues of insurance and employers' reimbursements of costs [8]. Guideline-based practice can radically reduce the cost of disease burden [10]. Above all, the proper utilisation of the healthcare units must be warranted by the government as well as the professional medical and pulmonary organisations for an effective COPD management. 
Toshita Kalkana ${ }^{1,2}$, Saibal Moitra ${ }^{1}$, Surinder K. Jindal ${ }^{3,4}$ and Subhabrata Moitra ${ }^{1,5}$

${ }^{1}$ Dept of Pneumology, Allergy and Asthma Research Centre, Kolkata, India. ${ }^{2}$ Dept of Biomedical Sciences, Shaheed Rajguru College of Applied Sciences for Women, Delhi, India. ${ }^{3}$ Dept of Pulmonary Medicine, Postgraduate Institute of Medical Education and Research, Chandigarh, India. ${ }^{4}$ Jindal Clinics, Chandigarh, India. ${ }^{5}$ Dept of Respiratory Medicine and Allergology, Lund University, Lund, Sweden.

Correspondence: Subhabrata Moitra, Respiratory Medicine and Allergology, Dept of Clinical Sciences, Faculty of Medicine, Lund University, BMC D12, Klinikgatan 30, Lund 22184, Sweden.

E-mail: subhabrata.moitra@med.lu.se

Received: Jan 262016 | Accepted after revision: March 122016

Conflict of interest: Disclosures can be found alongside this article at openres.ersjournals.com

$@$ ERSpublications

Battle against COPD: time to reinforce the primary healthcare units of rural areas of India to combat lung diseases http://ow.ly/ZAwge

Copyright (OERS 2016. This article is open access and distributed under the terms of the Creative Commons Attribution Non-Commercial Licence 4.0.

\section{References}

1 Murthy KJR, Sastry JG. Economic burden of chronic obstructive pulmonary disease. In: Background Papers: Burden of Disease in India. National Commission on Macroeconomics and Health Ministry of Health and Family Welfare Government of India, New Delhi. 2005; pp. 265-274. Available from: www.who.int/macrohealth/action/ NCMH_Burden\%20of\%20disease_(29\%20Sep\%202005).pdf.

2 World Health Organization. Health Topics: Global Burden of Disease. http://www.who.int/topics/global_burden_ of disease/en/. Date last accessed: March 28, 2016.

3 Lopez AD, Shibuya K, Rao C, et al. Chronic obstructive pulmonary disease: current burden and future projections. Eur Respir J 2006; 27: 397-412.

4 Salvi S, Apte K, Madas S, et al. Symptoms and medical conditions in 204912 patients visiting primary health-care practitioners in India: a 1-day point prevalence study (the POSEIDON study). Lancet Glob Health 2015; 3: e776-e784.

5 Mortimer K, Gordon SB, Jindal SK, et al. Household air pollution as a major avoidable risk factor for cardiorespiratory disease. Chest 2012; 142: 1308-1315.

6 Jindal SK. COPD: the unrecognized epidemic in India. J Assoc Physicians India 2012; 60 Suppl., 14-16.

7 Reddy KS, Patel V, Jha P, et al. Towards achievement of universal health care in India by 2020: a call to action. Lancet 2011; 377: 760-768.

8 Jindal SK. Promotion of standard treatment guidelines and building referral systems for management of common, non-communicable diseases in India. Indian J Community Med 2011; 36: Suppl. 1, S38-S42.

9 Bhome AB. COPD in India: iceberg or volcano? J Thorac Dis 2012; 4: 298-309.

10 Chillimuntha AK, Thakor KR, Mulpuri JS. Disadvantaged rural health- issues and challenges: a review. Natl J Med Res 2013; 3: 80-82. 